CASE REPORT

\title{
Oesophageal haematoma and associated Mallory-Weiss tear
}

\author{
C H Lim, S M Evereft
}

Postgrad Med J 2004;80:734-735. doi: 10.1136/pgmj.2003.018432

Intramural oesophageal haematoma is a rare condition that may present as vomiting or haematemesis. Mallory-Weiss tear has been proposed as a possible aetiology but the evidence to support this is circumstantial. A case of oesophageal haematoma associated with evidence of Mallory-Weiss tear on endoscopy that helps to support this hypothesis is presented.

ntramural oesophageal haematoma is a rare condition caused by blood dissecting the oesophageal mucosa from the underlying muscle. The cardinal symptom is severe chest pain that may mimic myocardial infarction or aortic dissection, though patients may present with symptoms of haematemesis, dysphagia, or odynophagia. ${ }^{12}$ Most reported cases of oesophageal haematoma have been spontaneous, secondary to trauma or endoscopic intervention, or have occurred with a background of coagulopathy. ${ }^{2-8}$ While some have suggested Mallory-Weiss tear as a possible aetiology, the evidence to support this is circumstantial. ${ }^{9}$ We present a case of oesophageal haematoma associated with Mallory-Weiss tear that adds support to this suspected aetiology.

\section{CASE REPORT}

An 81 year old woman presented with sudden onset of sharp chest pain, odynophagia, and epigastric pain followed by a few episodes of fresh haematemesis without melaena. Fresh blood was seen from the onset of vomiting. There was no previous history of upper gastrointestinal symptoms. She had been taking ibuprofen, and more recently celecoxib, a selective cyclo-oxygenase type 2 inhibitor non-steroidal antiinflammatory drug (NSAID) for osteoarthritis. She had also started aspirin one month earlier. On admission, her pulse was regular, 74 beats/min, blood pressure was 187/89 mm Hg and general physical examination was unremarkable. Her blood results were as follows: haemoglobin $147 \mathrm{~g} / \mathrm{l}$, platelets $601 \times 10^{9} / \mathrm{l}$, serum urea $9.3 \mathrm{mmol} / \mathrm{l}$, creatinine $83 \mu \mathrm{mol} / \mathrm{l}$, liver function parameters normal, and international normalised ratio 1.3. Chest radiography gave normal results.

Endoscopy carried out within 12 hours of admission revealed a large dark blue swelling, partially occluding the lumen, approximately $10-15 \mathrm{~mm}$ in diameter throughout the length of the oesophagus (fig 1). An $8 \mathrm{~mm}$ linear tear was seen at the gastro-oesophageal junction adjacent to the haematoma (fig 2). The rest of the stomach and duodenum were unremarkable. The tear was oozing fresh blood but haemostasis was achieved after injection of $2 \mathrm{ml}$ of adrenaline (1:10 000) and application of argon beam coagulation therapy. She had no further haematemesis while in hospital and was discharged home three days later. She remained well when seen in clinic two months later. A follow up endoscopy three months later showed complete resolution of the oesophageal haematoma and Mallory-Weiss tear (fig 3).

\section{DISCUSSION}

Oesophageal haematoma is a rare finding at endoscopy. The diagnosis is normally made with appearances of mucosal discolouration and swelling in the mid/distal oesophagus. Although appearances are usually characteristic, oesophageal haematoma can be confused with oesophageal varices or tumour, in which case computed tomography or endoscopic ultrasound may help to establish the diagnosis. ${ }^{10}{ }^{11}$ The aetiology of submucosal haematoma is uncertain. Some suggest that it is a distinct clinical entity, separate in aetiology to Mallory-Weiss tear and Boerhaave's syndrome. ${ }^{12}$ This is supported by the fact that oesophageal haematoma tends to occur in an older age group and is more common in females than these other conditions..$^{12}$ On the other hand, others have proposed that Mallory-Weiss tear is a possible cause. This is suggested by the predominantly distal location of oesophageal haematomas ${ }^{9}$ and prodromal symptoms consistent with Mallory-Weiss tear. ${ }^{13}$

In two review papers, with a total case series of 36 patients, symptoms such as vomiting, retching, or coughing were found in $50 \%-70 \%$ of patients, consistent with Mallory-Weiss tear. ${ }^{14}$ Patients without such symptoms were frequently found to have coagulopathies. ${ }^{9}$ These observations suggest that trauma may lead to a distal oesophageal mucosal tear and formation of a haematoma that extends proximally, but that such trauma is minimal or unnecessary in patients with impaired haemostasis. These latter cases are often described as spontaneous. ${ }^{9}$ However, such hypotheses have hitherto only been based on clinical features without other corroborating evidence.

In this report we present a case of oesophageal haematoma in which endoscopic appearances suggest coexisting MalloryWeiss tear. Other factors that may have contributed to formation of oesophageal haematoma in this case include aspirin and NSAID ingestion. The degree of blood loss was minimal, though endoscopic treatment was required and the patient settled with otherwise conservative management. These features, as well as female gender, older age group, and preceding vomiting and haematemesis are similar to those in

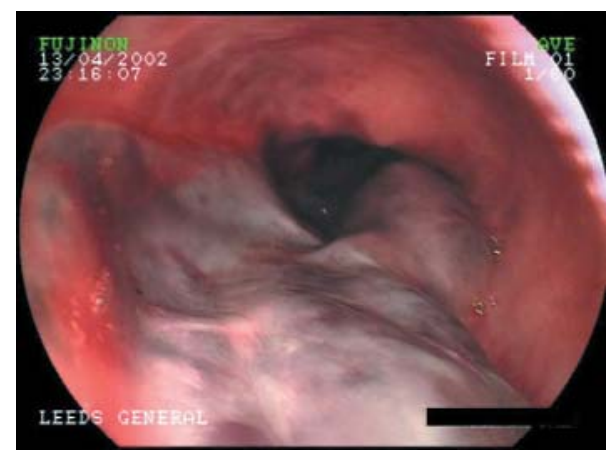

Figure 1 Oesophageal haematoma. 


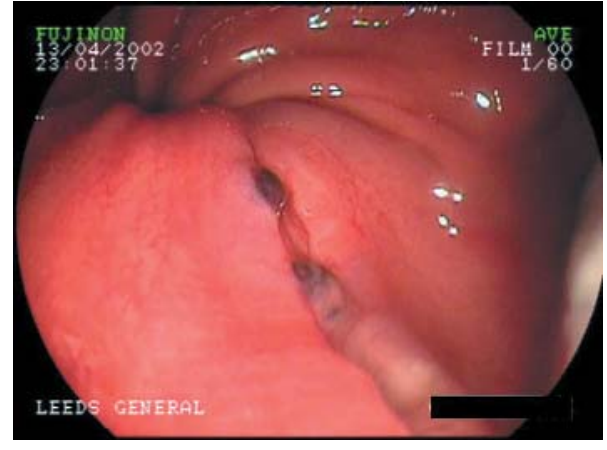

Figure 2 Mallory-Weiss tear.

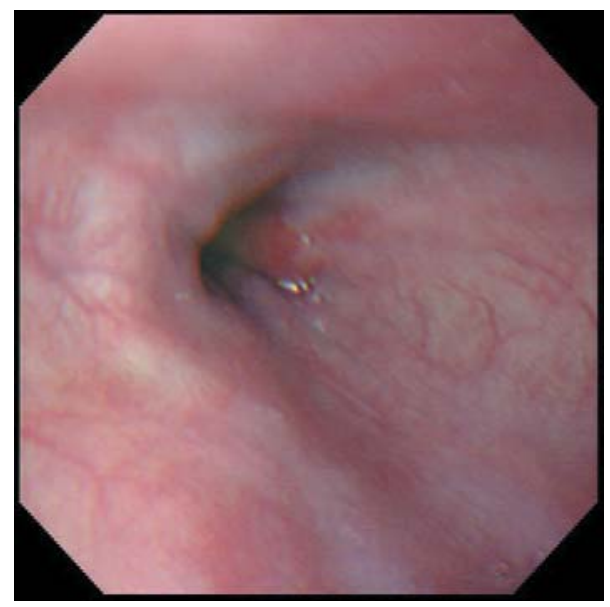

Figure 3 Follow up endoscopy three months later.

the reported literature. ${ }^{12}$ However, the association with Mallory-Weiss tear on endoscopy has not previously been reported. Thus, the clinical presentation and endoscopic findings suggest that the oesophageal haematoma occurred either as a result of, or concomitant with, a Mallory-Weiss tear. Although it is possible that the Mallory-Weiss tear was caused by pressure from the haematoma, this is unlikely because the tear was distal to and separate from the haematoma.

There are two possible roles for Mallory-Weiss tear in the aetiology of these haematomas. If the tear is large it may extend intramurally, facilitating extension of the haematoma proximally into the oesophagus. Alternatively the tear may be superficial but the bleeding is heavy and dissects the oesophageal mucosa from the underlying muscle. It is possible that this is also relevant to spontaneous haematomas, which have no preceding symptoms of vomiting, retching, or injury. ${ }^{15}{ }^{16}$ This group of patients often has a history of aspirin ingestion or impaired haemostasis, ${ }^{9}$ and it may be that some of these cases could also be initiated with a Mallory-Weiss tear that had healed by the time of endoscopy.

In conclusion, therefore, we have shown clinical and photographic corroboration of Mallory-Weiss tear with

\section{Learning point}

The appearance of oesophageal haematoma may be mistaken for more severe conditions such as oesophageal varices or tumour. Hence, it is important to recognise the characteristic appearance as the management is usually conservative, whereas it is not for oesophageal varices.

oesophageal haematoma. We believe that this case supports the hypothesis that Mallory-Weiss tear may be important in the pathogenesis of many cases of intramucosal oesophageal haematoma, the formation of which may depend on the presence and severity of two factors: oesophageal mucosal trauma and impaired haemostasis.

\section{Authors' affiliations}

C H Lim, S M Everett, Centre for Digestive Disease, Leeds General Infirmary, Leeds, UK

Correspondence to: Dr Chee H Lim, Room 190A, Gastroenterology Department, Clarendon Wing, Leeds General Infirmary, Leeds LS1 3EX, UK; ch.lim@virgin.net

Submitted 29 December 2003

Accepted 10 February 2004

\section{REFERENCES}

1 Smith G, Brunnen PL, Gillanders LA, et al. Oesophageal apoplexy. Lancet 1974;i:390-2.

2 Yapa RS, Green GJ. Spontaneous oesophageal haematoma presenting as acute myocardial infarction: implications for thrombolytic therapy. Postgrad Med J 1991;67:779-80.

3 Hanson JM, Neilson D, Pettit SH. Intramural oesophageal dissection. Thorax $1991 ; 46: 524-7$

4 Hess U, Brucher BL, Cavallaro A, et al. Intramural esophageal hematoma after cardioversion. Dis Esophagus 1997; 10:225-8.

5 Meier JH, Zeitlin JH, Smith MT. Post-sclerotherapy intramural esophageal hematoma: endoscopic and radiologic findings. Gastrointest Endosc 1992;38:102-3.

6 Piccione PR, Winkler WP, Baer JW, et al. Pill-induced intramural esophageal hematoma. JAMA 1987;257:929.

7 Smart RF, Stone AR. Intramural oesophageal haematoma complicating anticoagulant therapy. N Z Med J 1978;87:176-7.

8 Yamashita K, Okuda H, Fukushima H, et al. A case of intramural esophageal hematoma: complication of anticoagulation with heparin. Gastrointest Endosc 2000;52:559-61.

9 Shay SS, Berendson RA, Johnson LF. Esophageal hematoma. Four new cases, a review, and proposed etiology. Dig Dis Sci 1981;26:1019-24.

10 Mion F, Bernard G, Valette PJ, et al. Spontaneous esophageal hematoma: diagnostic contribution of echoendoscopy. Gastrointest Endosc 1994;40:503-5.

11 Schweiger F, Depew WT. Spontaneous intramural esophageal hematoma. Diagnosis by CT scanning. J Clin Gastroenterol 1987;9:546-8.

12 Folan RD, Smith RE, Head JM. Esophageal hematoma and tear requiring emergency surgical intervention. A case report and literature review. Dig Dis Sci 1992;37:1918-21

13 Knauer CM. Mallory-Weiss syndrome. Characterization of 75 Mallory-weiss lacerations in 528 patients with upper gastrointestinal hemorrhage. Gastroenterology 1976;71:5-8.

14 Mclntyre AS, Ayres R, Atherton J, et al. Dissecting intramural haematoma of the oesophagus. Q J Med 1998;91:701-5.

15 Hiller N, Zagal I, Hadas-Halpern I. Spontaneous intramural hematoma of the esophagus. Am J Gastroenterol 1999;94:2282-4.

16 Van Laethem JL, Deviere J, Cremer M. Serial endoscopic findings of spontaneous intramural hematoma of the esophagus. Endoscopy 1997;29:44-6. 